\title{
$\operatorname{CONF-970834--8}$
}

\section{The Examunation of Calcium Ion Implanted Alumgna with Energy Filtered Transmission EleCtron MicRosCOPY}

\author{
E. M. Hunt *, J. M. Hampikian *, N. D. Evans ** \\ *School a Materials Science and Engineering, Georgia Institute of Technology, Atlanta, GA 30332-0245 \\ **Oak Ric ge Institute for Science and Education, P.O. Box 117, Oak Ridge, TN 37831-0117
}

Ion implantation can be used to alter in the optical response of insulators through the formation of embedded nano-sized particles. Single crystal alumina has been implanted at ambient temperature with $50 \mathrm{keV} \mathrm{Ca}{ }^{+}$to a fluence of $5 \times 10^{16}$ jons $/ \mathrm{cm}^{2}$. Ion channeling, $\mathrm{Knoop}$ microhardness measurements, and transmission electron microscopy (TEM) indicate that the alumina surface layer was amorphized by the implant. TEM also revealed nano-sized crystals $\approx 7-8 \mathrm{~nm}$ in diameter as seen in Figure 1. These nanocrystals are randomly oriented, and exhibit a face-centered cubic structure (FCC) with a lattice parameter of $0.409 \mathrm{~nm} \pm 0.002 \mathrm{~nm}$. The similarity between this crystallography and that of pure aluminum (which is FCC with a lattice parameter of $0.40 \mathrm{~nm}$ ) suggests that they are metallic aluminum nanocrystals with a slightly dilated lattice parameter, possibly due to the incorporation of a small amount of calcium. Energy-filtered transmission electron microscopy (EFTEM) provides an avenue by which to confirm the metallic nature of the aluminum involved in the nanocrystals. Experiments were performed with a Gatan Imaging Filter (GIF ${ }^{\mathrm{TM}}$ ) interfaced to a Philips CM 30 TEM operated at $300 \mathrm{kV}$. The gain normalized images were $512 \times 512$ pixels in size, and were recorded with an exposure time of 1 second and an energy window of $5-\mathrm{eV}$. 'The component in the 15-eV loss images due to alumina valence excitation was estimated from adjacent loss images and subtracted ${ }^{2}$.

Three singl s scattering energy loss distributions from material standards are shown in Fig. $2^{3}$. The valence-loss spectrum from $\mathrm{Al}_{2} \mathrm{O}_{3}$ (a) shows a large loss feature at $\sim 25 \mathrm{eV}$. The plasmon loss spectrum taken from $\mathrm{Al}$ (b) shows an energy loss peak at $\sim 15 \mathrm{eV}$. The Ca valence-loss spectrum (c) also exhibits a small feature at $\sim 15 \mathrm{eV}$. A typical spectrum from the implanted sample contains major loss features at both 25 and $15 \mathrm{eV}$ (not shown). This raises the possibility of the presence of calcia in the implanted region. However, the calcia valence-loss spectrum also contains a strong feature at $-40 \mathrm{eV}$. This $40-\mathrm{eV}$-loss feature is not evident in a typical spectrum from the implanted sample. A zero-loss image of the implanted sample is shown in Fig. 3a. A 15-eV-loss image, seen in Fig. $3 \mathrm{~b}$, indicates that the crystals contain metallic aluminum. In a $25-\mathrm{eV}$-loss image from the same region (Fig 3c), the same features are slightly darker than the surrounding matrix. This image confirms that the particles are not alumina. Fig. 4 shows the oxygen "jump-ratio" image (post-edge divided by pre-edge) from an area similar to the area in Fig 3. This type of image yields information similar to that of an elemental map in that the dark areas have a low ratio value which indicates a deficiency in the element of interest. Therefore, this image shows that the particle regions are oxygen deficient with respect to the matrix material. Figure 5 shows a calcium "jump-ratio" image which indicates that the particle regions are calcium deficient. The large "halos" around the particle positions may indicate calcium enrichment in the immediatley surrounding matrix, however it may also be the result of focusing difficulties due to the low beam intesity at the high energy loss values (346-350 eV) required for imaging the Ca L2-3 edge.

EFTEM has confirmed that the aluminum present in the particles is metallic in nature, that the particles are cxygen deficient in comparison with the matrix material and that the particles are deficient in calcium, and therefore not likely to be calcia. The particles thus appear to be FCC Al (possibly alloyed with a few percent $C a$ ) with a lattice parameter of $0.409 \mathrm{~nm}$. A similar result was obtained for yttrium ion implantation into alumina ${ }^{4}$.

1. E.M. Hunt, et. al., Mat. Res. Soc. Symp. Proc., 396, p. 403-410 (1995)

2. N.Evans, et. al., Proc. Microscopy and Microanalysis 1995, p. 266-7 (1995)

3. C.C. Ahn, O.L. Krivanek, "EELS Atlas", (Gatan Inc., Warrendale, PA and Center for Solid State Science, Arizona State Univ., Tempa, AZ, 1983).

4. E.M. Hunt, et. a!., Proc. Microscopy and Microanalysis 1996, p.534-35 (1996)

DISTRIBUTION OF THIS DOCUMENT IS UNLIMITED

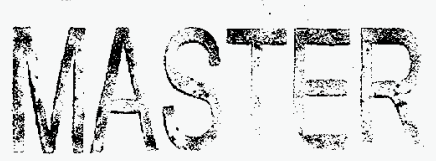

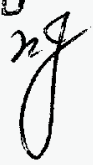

"The submitted manuscript has been authored by a contractor of the U.S. Government under contract No. DE-AC05-960R22464. Accordingly, the U.S.

Government retains a nonexclusive, royalty-free license to publish or repraduce the published form of this contribution, or allow others to do so, for U.S. Government purposes." 
5. Research sponsored in part by the National Science Foundation under Grant No. DMR-9624927 and the Division of Materials Sciences, U.S. Dept. of Energy, under contract DE-AC05-960R22464 with Lockheed Martin Energy Research Corp, through the SHaRE Program under the contract DE-AC05-760R00033 with Oak Ridge Associated Universities, and by the Office of Naval Research through the Molecular Design Institute at Georgia Institute of Technology.

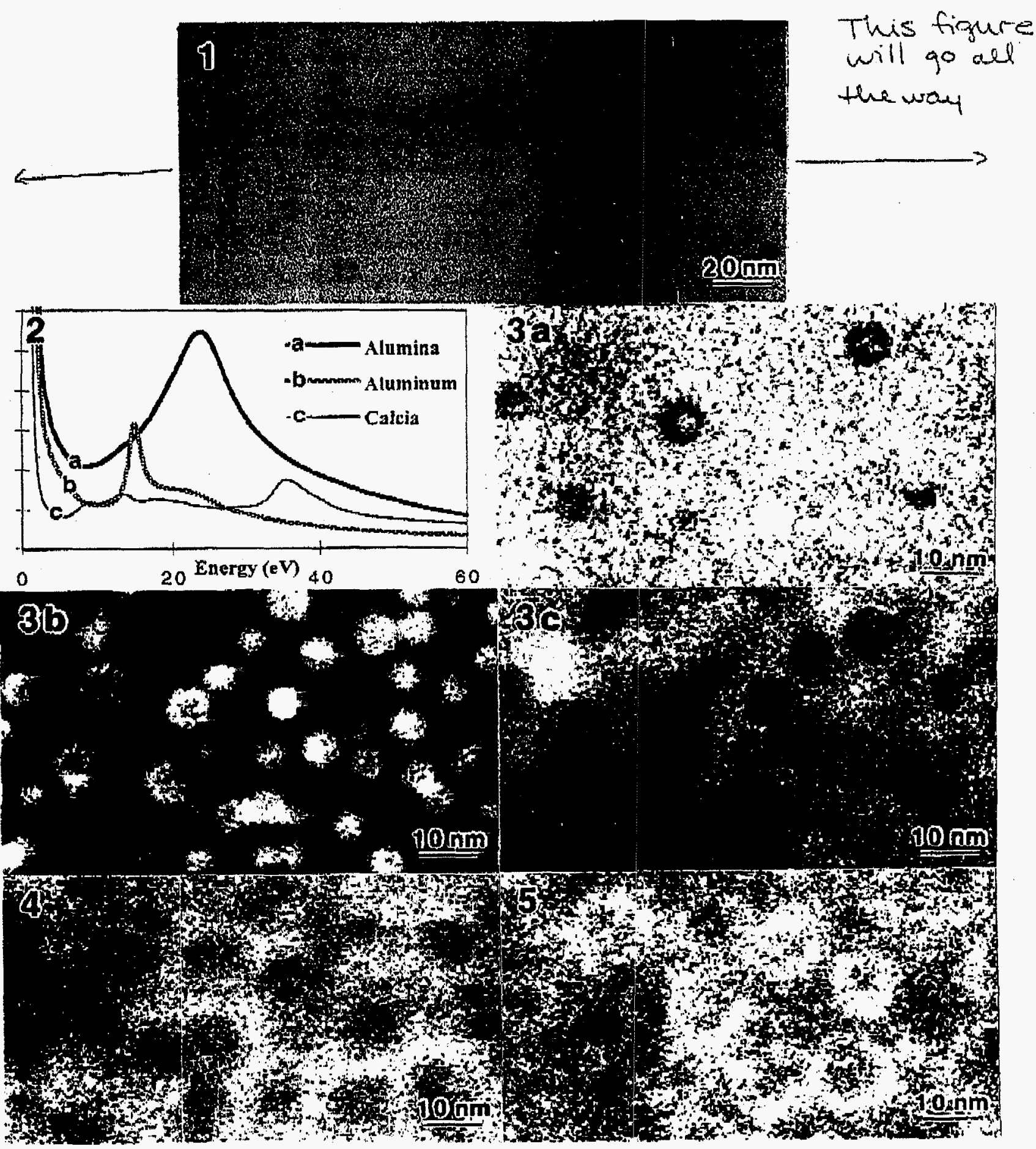




\section{DISCLAIMER}

This report was prepared as an account of work sponsored by an agency of the United States Government. Neither the United States Government nor any agency thereof, nor any of their employees, makes any warranty, express or implied, or assumes any legal liability or responsibility for the accuracy, completeness, or usefulness of any information, apparatus, product, or process disclosed, or represents that its use would not infringe privately owned rights. Reference herein to any specific commercial product, process, or service by trade name, trademark, manufacturer, or otherwise does not necessarily constitute or imply its endorsement, recommendation, or favoring by the United States Government or any agency thereof. The views and opinions of authors expressed herein do not necessarily state or reflect those of the United States Government or any agency thereof. 


\section{DISCLAMMER}

Portions of this document may be illegible in electronic image products. Images are produced from the best available original document. 